\title{
APPLICATIONS OF ONE INEQUALITY TO MEASURES OF NON-COMPACTNESS AND NARROW OPERATORS
}

\author{
NinA A. ERZAKOVA
}

Abstract. We consider a generalization of an inequality from papers by Yu. A. Dubinskii, J.L. Lions and E. Magenes. This inequality is of great importance for the proof of solvability of nonlinear elliptic and parabolic equations. In contrast to their works, we do not require the compactness of the embedding. We suggest a new approach to the problem of narrow operators. In particular, we find a new application of measures of non-compactness.

Mathematics subject classification (2010): Primary 47H08, Secondary 46B50, 46E30, 47J20, 47A50. Keywords and phrases: Separation measure of non-compactness, metric spaces, narrow operators, compact operators.

\section{REFERENCES}

[1] R. R. Akhmerov, M. I. Kamenskil̆, A. S. Potapov, A. E. Rodkina and B. N. SadovskiĬ, Measures of noncompactness and condensing operators, Birkhäuser, Basel, Boston, Berlin, 1992.

[2] J. ApPell And E. De Pascale, Su alcuni parametri connessi con la misura di noncompatezza di Hausdorff in spazi di funzioni misurabili, Boll. Unione Mat. Ital. 3, B (1984), 497-515.

[3] J. M. Ayerbe Toledano, T. Domínguez Benavides and G. López Acedo, Measures of noncompactness in metric fixed point theory, Birkhäuser, Basel, Boston, Berlin, 1997.

[4] J. BAnaś AND K. GoeBel, Measures of noncompactness in Banach spaces, Marcel Dekker, Lecture Notes in Pure and Applied Mathematics 60, New York, Basel, 1980.

[5] YU. A. DUBINSKII, Weak convergence for nonlinear elliptic and parabolic equations [in Russian], Mat. Sb. (N.S.) 67 (109), 4 (1965), 609-642.

[6] N. A. ERZAKova, Measures of noncompactness in the investigation of inequalities, Iz. VUZ. Mat. 2000, 9, 3-8. Engl. transl.: N. A. Erzakova, Measures of noncompactness in the investigation of inequalities, Russian Math. (Iz. VUZ), 44, 9 (2000), 1-6.

[7] N. A. ErZakova, Compactness with Respect to a Measure and a Measure of Noncompactness, Sib. Matem. Zhurn. 38, 5 (1997), 1071-1073. Engl. transl.: Erzakova N. A., Compactness with respect to a measure, and a measure of noncompactness, Siberian Math. J., 38, 5 (1997), 926-928.

[8] N. A. ErZakova, On Measure-Compact Operators, Izv. Vysš. Učebn. Zaved. Matematika 2011, 9, 44-51. Engl. transl.: Russian Math. (Iz. VUZ) 55, 9 (2011), 37-42.

[9] N. A. ERZAKova, On locally condensing operators, Nonlinear Anal. 75, 8 (2012), 3552-3557.

[10] N. A. ERZAKova, Measures of noncompactness in regular spaces, Canad. Math. Bull. 57 (2014), 780-793.

[11] N. A. Erzakova, Generalization of some M. A. Krasnosel'skii's results, J. Math. Anal. Appl. 428 (2015), 1368-1376.

[12] N. A. ERZakova And M. VÄth, On strongly condensing operators, Annali di Matematica Pura ed Applicata (1923): 196, 1 (2017), 309-323. doi:10.1007/s10231-016-0573-8.

[13] V. Kholomenyuk, V. Mykhaylyuk and M. Popov, On isomorphisms of some Köthe function F-space, Cent. Eur. J. Math. 9, 6 (2011), 1267-1275.

[14] M. A. Krasnoselskil̆, P. P. Zabrĕ̌Ko, E. I. Pustylnik and P. E. SobolevskiĬ, Integral operators in spaces of summable functions, (in Russian) Nauka, Moscow, 1958. Engl. transl.: Noordhoff, Leyden, 1976. 
[15] J.-L. Lions, Quelques methodes de resolution des Problemes aux Limites non lineaires, Dunod, Gauthier-Villars, Paris, 1969.

[16] J.-L. Lions And E. Magenes, Problémes aux limites non homogénes et applications, Dunod, Paris, 1968.

[17] O. V. Maslyuchenko, V. V. Mykhaylyuk and M. M. Popov, A lattice approach to narrow operators, Positivity 13 (2009), 459-495.

[18] A. M. PlichKo AND M. M. Popov, Symmetric function spaces on atomless probability spaces, Dissertationes Math. (Rozprawy Mat.), 306 (1990), 1-85.

[19] M. M. Popov and B. Randrianantoanina, Narrow Operators on Function Spaces and Vector Lattices, De Gruyter Studies in Mathematics 45, Berlin, 2013.

[20] M. V̈̈TH, Ideal spaces, Lect. Notes Math. 1664, Springer, Berlin, Heidelberg, 1997.

[21] M. VÄтн, Volterra and integral equations of vector functions, Marcel Dekker, New York, Basel, 2000.

[22] N. A. Yerzakova, On Measures of Non-Compactness in Regular Spaces, Z. Anal. Anw. 15, 2 (1996), 299-307. 